control groups. When only BCG-treated patients are considered, however, the improvement in immunological responsiveness to recall antigens was much greater in those who relapsed than in those who sustained their remission. The same phenomenon was seen, but to a lesser extent, in controls. This unexpected result seems to refute the assumption that adjuvant-induced improvement in overall immune reactivity is beneficial. It might be conjectured that in relapsing patients either tumour immunity was not stimulated at the same time as general immunity-for example, because most of the immunocompetent cells were committed to react against more powerful microbial antigens or because, with respect to tumour-directed reactions, stimulation of suppressor elements of the immune system predominatedor blocking factors were simultaneously increased. A further possibility is that the degree of tumour-directed immune reactivity induced in BCG-treated patients who relapsed actually stimulated tumour growth; this has been described in animals. ${ }^{30} 31$ Our findings indicate that tumour immunity is not necessarily reflected by general immunity-in fact the reverse may sometimes apply-and further emphasise the potential risks of enhancing tumour growth by "therapeutic" immunological manipulation.

We thank the staff of the Lymphoma Treatment Centre, Kampala, for their skilled help. Dr C Olweny helped with the care of some of the patients, and Mr A Kisuule directed follow-up. Sera were tested for anti-VCA and anti-EA by Dr W Henle, Children's Hospital of Philadelphia, and for anti-membrane antigen by Dr P Gunven, Karolinska Institute, Stockholm. Dr R Herberman, National Cancer Institute, Bethesda, provided Burkitt's lymphoma cell lines. Mrs P Magrath provided both clinical and administrative help throughout the trial. This work was supported in part by contract NCI-CM-71343 from the National Cancer Institute, Bethesda, Maryland, and by the Cancer Research Campaign (UK).

\section{References}

${ }^{1}$ Ziegler, J L, Cancer, 1972, 30, 1534.

2 Ziegler, J L, et al, Cancer Research, 1972, 32, 1267.

3 Ziegler, J L, et al, Cancer, 1970, 26, 474.

4 Ziegler, J L, et al, International fournal of Cancer, 1972, 10, 254

5 Burkitt, D P, Cancer, 1967, 20, 756.

${ }^{6} \mathrm{Klein}, \mathrm{G}$, in Burkitt's Lymphoma, ed D P Burkitt and D H Wright. London, Livingstone, 1970.

${ }^{7}$ Stjernsward, J, Clifford, P, and Svedmyr, E, in Burkitt's Lymphoma, ed D P Burkitt and D H Wright. London, Livingstone, 1970.

${ }^{8}$ Bluming, A Z, et al, Clinical and Experimental Immunology, 1971, 9, 713.

- Fass, L, Herberman, R B, and Ziegler, J L, New England fournal of Medicine, 1970, 19, 282

${ }_{10}$ Berard, C, et al, Bulletin of the World Health Organisation, 1969, 80, 601.

${ }^{11}$ Magrath, I T, British fournal of Cancer, 1973, 28, 477.

12 Ziegler, J L, and Bluming, A Z, British Medical fournal, 1971, 3, 108.

${ }^{13}$ Ziegler, J L, et al, Cancer Chemotherapy Reports, in press.

${ }^{14}$ Mathé, E, Pouillart, P, and Lapeyraque, F, British fournal of Cancer, $1969,23,814$

${ }^{15}$ Henle, G, and Henle, W, fournal of Bacteriology, 1966, 91, 1248.

${ }^{16}$ Henle, G, Henle, W, and Klein, G, International fournal of Cancer, $1971,8,272$.

${ }^{17}$ Gunven, P, and Klein, G, fournal of the National Cancer Institute, 1971, $47,559$.

${ }^{18}$ Magrath, I T, International fournal of Cancer, 1974, 13, 839.

19 Ziegler, J L, and Magrath, I T, National Cancer Institute Monograph, $1973,39,199$.

${ }^{20}$ Magrath, I T, et al, British Medical fournal, 1974, 2, 308.

${ }^{21}$ Ziegler, J L, and Magrath, I T, in Pathobiology Annual, ed H L Joachim, p 129. New York, Appleton-Century-Cofts, 1974.

${ }^{22}$ Gunven, P, MD Thesis, 1974, Department of Tumour Biology, Karolinska Institute, Stockholm.

${ }^{23}$ Bast, R C, et al, New England fournal of Medicine, 1974, 290, 1458

${ }^{24}$ Baldwin, R W, and Pimm, M V, British fournal of Cancer, 1973, 27, 48.

${ }^{25}$ Parr, I, British fournal of Cancer, 1972, 26, 174.

${ }^{26}$ Hanna, M G, et al, fournal of the National Cancer Institute, 1973, 51, 1897.

${ }^{27} \mathrm{Zbar}, \mathrm{B}$, et al, Fournal of the National Cancer Institute, 1972, 49, 119.

${ }^{28} \mathrm{Ngu}, \mathrm{V}$ A, Burkitt, D P, and Osunkoya, B O, in Burkitt's Lymphoma, ed D P Burkitt and D H Wright. London, Livingstone, 1970.

${ }^{29}$ Klein, G, et al, fournal of the National Cancer Institute, 1967, 39, 1027.

${ }^{30}$ Prehn, R, Science, 1972, 176, 170.

31 Jeejeebhoy, H F, International fournal of Carcer, 1974, 13, 665.

\title{
Detection of deep vein thrombosis by Doppler angiography
}

\author{
T K DAY, P J FISH, V V KAKKAR
}

British Medical fournal, 1976, 1, 618-620

\section{Summary}

A new technique, ultrasonic Doppler angiography, was used to examine the deep veins in 50 legs of 40 patients in which deep vein thrombosis was suspected. The results were compared with those of venography. The ultrasound method detected 30 out of 32 venographically confirmed thrombi and showed 17 out of 18 venographically proved normal deep veins. It was equally effective in detecting partial as well as totally occluding thrombi.

\section{Introduction}

The continuous wave ultrasonic Doppler blood-flow detector is a simple instrument for the non-invasive examination of the

King's College Hospital Medical School, London SE5 8RX

T K DAY, MB, MRCP, research fellow

P J FISH, MSC, physicist

V V KAKKAR, FRCS, FRCS ED, consultant surgeon

deep veins of the legs. ${ }^{1-3}$ It is unreliable, however, when used in screening for early, forming asymptomatic thrombi or for confirming the presence of suspected deep vein thrombosis. ${ }^{4}$ The dangerous, partially occluding thrombus likely to produce major pulmonary embolism may be missed because of the difficulty in distinguishing between normal venous flow signals and signals produced by blood passing by a non-occluding thrombus. ${ }^{5}$

Ultrasonic Doppler angiography, ${ }^{6} 7$ a method of imaging the lumen of suspect blood vessels by using ultrasound and the Doppler effect, overcomes the disadvantages of the conventional ultrasonic flow detector while maintaining its advantages. The apparatus consists of a pulsed ultrasonic flow detector and a B-scanner. Such an instrument has been used to detect lesions in arteries. ${ }^{8} 9$ We report here our assessment of the accuracy of ultrasonic angiography as compared with that of phlebography in detecting deep vein thrombosis in cases suspected clinically.

\section{Patients and method}

\section{PATIENTS}

Forty patients with clinical features suggestive of deep vein thrombosis or pulmonary embolism or both referred from medical, 
surgical, and gynaecological wards were studied. A form was completed for each patient, recording age, sex, and presenting symptoms and signs.

\section{ULTRASONIC ANGIOGRAPHY}

The technique used is described in detail elsewhere. ${ }^{10} \mathrm{~A}$ diagram of the apparatus is shown in fig 1 . The flow detector indicates the presence and direction of flow at 30 "flow-detection points" along an ultrasound beam projected into the body from a probe placed on the skin. When flowing blood is detected at a point a spot in a corresponding position on the cathode-ray screen of the storage monitor is intensified and stored. The position of the spot is determined by signals from a position computer. This unit combines information on the ultrasound beam position from a resolver to which the probe is mechanically coupled and information on the detection point position along the ultrasound beam and direction of flow from the flow detector.

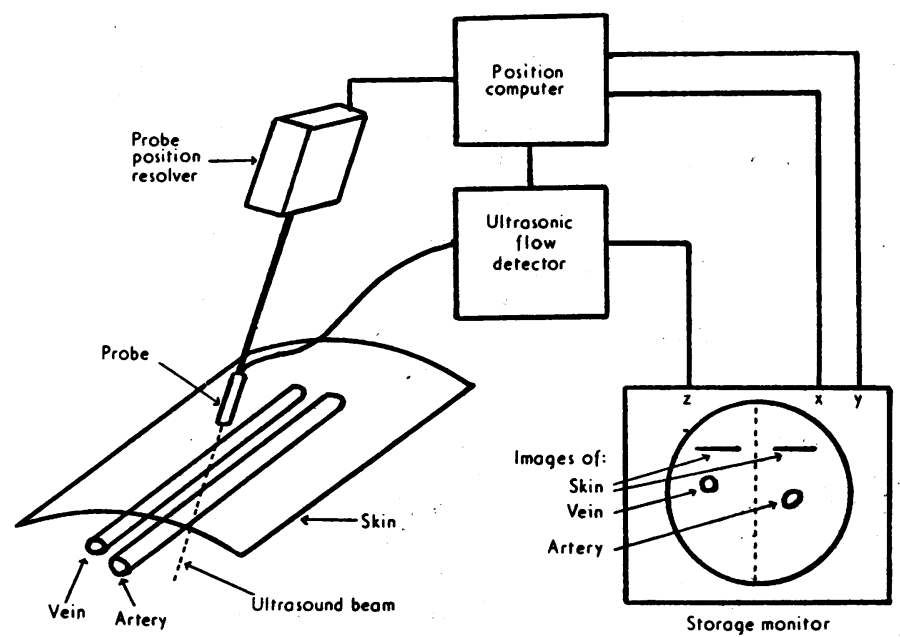

FIG 1-Diagram of ultrasonic vessel-imaging system. $z=$ Brightness modulation input. $x=$ Horizontal deflection. $y=$ Vertical deflection.

Images of blood vessels carrying blood moving along the beam towards the probe appear on the right side of the screen, and those carrying blood moving along the beam away from the probe appear on the left. Thus images of contiguous veins and arteries are separated. To enable the depth of a vessel to be measured the position of the skin surface is indicated on the screen. A picture of a blood vessel is built up on the storage monitor by moving the probe across the skin, so that the beam sweeps through the vessel. Lateral, anteroposterior, and cross-sectional images may be generated, but only cross-sectional images were used in this trial.

Patients were examined while relaxed and supine. Because deep venous flow in patients at rest is inadequate for filling out the veins completely it was augmented by a pneumatic pressure cuff wrapped round the midcalf. This cuff, when inflated, had the effect of emptying the calf veins and thus augmenting flow in the popliteal and femoral veins. The cuff was inflated automatically by compressed air every five seconds (being the shortest time for adequate filling of the calf veins ${ }^{11}$ ), the air flow to and from the cuff being controlled by a solenoid operated by a pulse generator.

The end of the probe was covered with KY jelly and mounted in the position resolver. The skin overlying the vessel to be examined was smeared with KY jelly and the probe placed on the skin. The probe was passed transversely across the vessel and its image appeared on the screen. When the scan had been completed the instrument was switched off and a Polaroid photograph taken of the stored image. Images were obtained of both femoral and both popliteal veins.

\section{VENOGRAPHY}

All the patients had their veins examined by venography. The technique used has been described. ${ }^{12}$

\section{Results}

\section{DOPPLER ANGIOGRAPHY}

Fifty legs of the 40 patients (10 having bilateral disease) were examined. The Doppler angiograms were interpreted according to three criteria: (1) the diameter of the deep venous image-normal veins are of the same diameter or slightly larger than the accompanying artery and are of equal diameter in both legs; (2) the position of the venous image-the femoral or popliteal vein is found at the same depth as the artery or slightly deeper, whereas collaterals are more superficial; and (3) flow augmentation-inflation of the calf cuff produces enhanced venous flow, which is equal in both limbs when these are normal; augmentation is usually reduced or absent in limbs with deep vein thrombosis.

The following four patterns were seen.

Normal-The cross-sectional image of the deep vein was of the expected size. It was identified by its position relaitve to the arterial image.

Partial occlusion-The image of the vein appeared at the expected position but its cross-sectional area was reduced.

Total occlusion-Complete occlusion was indicated by the absence of an image in the expected position.

Reversed flow-This was characterised by a venous image on the "arterial" (right) side of the screen when the calf cuff pressure was released. Reversed flow indicated the absence or incompetence of the venous valve, probably as a result of recanalisation of an old thrombus with valve destruction.

Examples of the Doppler angiograms and corresponding $x$-ray venograms falling into two of the above catergories (normal and totally occluded) are shown in fig 2 . The presence of thrombi in the popliteal and femoral veins was diagnosed when the patterns characteristic of partial or total occlusion were seen.

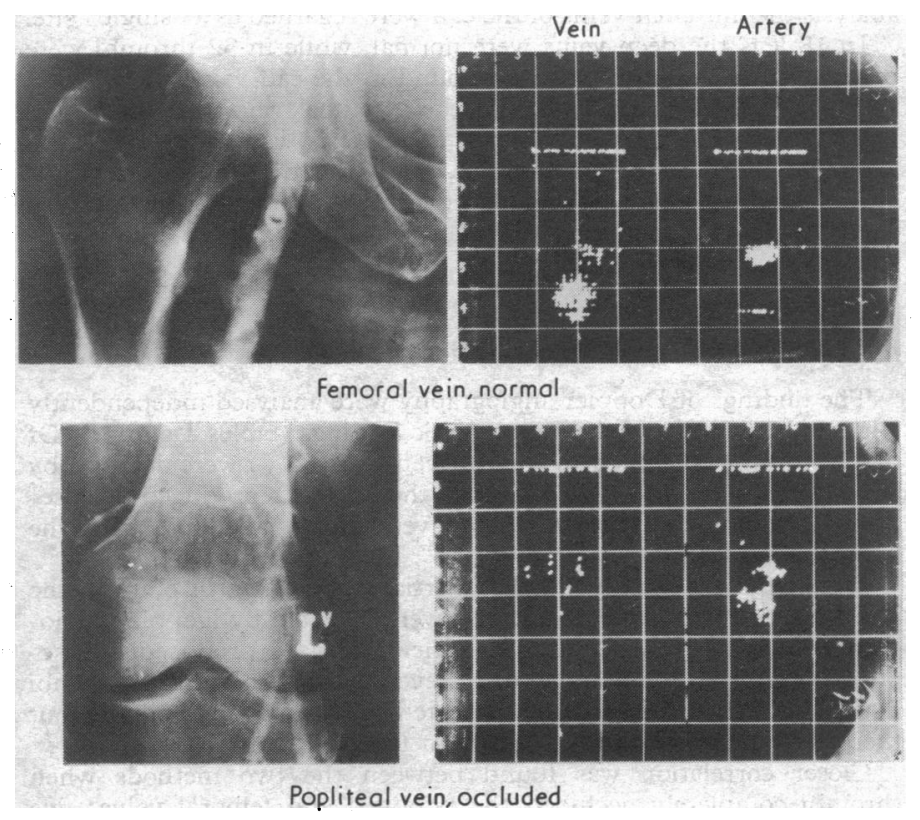

FIG 2-Doppler angiograms and corresponding $x$-ray venograms showing normal femoral vein (top) and totally occluded popliteal vein (bottom). NB. Images on venous and arterial sides of screen must be mentally superimposed to obtain correct anatomical relationship of vein and artery.

Table I gives the results of Doppler angiography of the 50 legs. In 19 legs Doppler angiography showed a normal pattern, and in 31

TABLB I-Overall correlation of Doppler angiography and venographic findings

\begin{tabular}{|c|c|c|c|c|c|c|}
\hline & & & & \multirow{2}{*}{$\begin{array}{l}\text { Total } \\
\text { legs }\end{array}$} & \multicolumn{2}{|c|}{ Doppler angiography } \\
\hline & & & & & DVT & No DVT \\
\hline Venography $\}$ NV DV DVT & 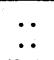 & $\because$ & $\because$. & $\begin{array}{l}32 \\
18\end{array}$ & $\begin{array}{c}30 \\
1\end{array}$ & 17 \\
\hline Total legs & .. & .. & .. & 50 & 31 & 19 \\
\hline
\end{tabular}


legs it indicated the presence of thrombi. The method indicated both complete and partial occlusions (table II) and showed a pattern of reversed flow only in six legs.

TABLE II-Proportion of thrombi detected by Doppler angiography according to type and extent of thrombosis

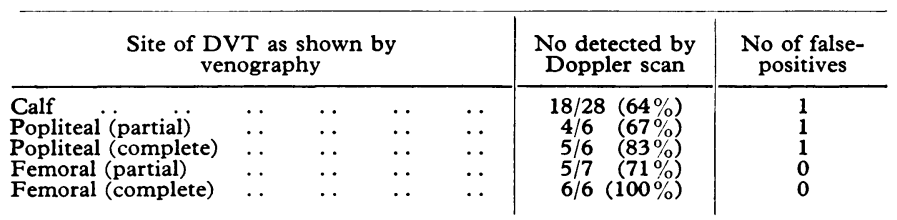

\section{VENOGRAPHY}

Bilateral phlebography was performed on 10 of the 40 patients. Good visualisation of the deep veins up to and including the iliac veins was obtained in all the legs examined. In four patients-all with thrombosis of the femoral vein-the external and common iliac veins were not seen. Criteria for the diagnosis of thrombosis included persistence of a filling defect in a well-opacified vein that remained unchanged in shape and location during fluoroscopy and in two separate radiographs.

The following information was accurately recorded: the site of the thrombosis; whether it was confined to the calf (minor) or included the popliteal or more proximal veins (major); the anatomical distribution of thrombi in the deep veins; and, finally, whether the thrombotic process affected continuous venous segments or multiple separate sites (discontinuous thrombosis). For the purpose of this analysis the muscular veins of the calf were regarded as a "single" site.

In 18 legs the deep veins were normal, while in 32 thrombi were present. In 28 legs thrombi were found in the calf veins; in addition 24 of these also had thrombi in the popliteal vein $(12 \mathrm{limbs})$ and femoral vein (13 legs). In one leg thrombosis was seen to affect the whole of the deep venous system, including the iliac veins. Thus altogether 53 thrombi were detected in the 32 limbs; their naturepartially or totally occluding-is shown in table II.

\section{DOPPLER ANGIOGRAPHY $v$ VENOGRAPHY}

The findings of Doppler angiography were analysed independently without knowledge of the venographic findings (tables I and II). Of the 28 thrombi confined to the calf veins $18(64 \%)$ were detected by the Doppler method. In addition, the method produced a falsepositive result in one patient in whom venography failed to confirm the indication of thrombi.

In six legs venography showed partially occluding thrombi in the popliteal veins; four of these $(67 \%)$ were detected by Doppler angiography, while in one additional patient it again produced a falsepositive result. Similarly, five out of seven partially-occluding thrombi in the femoral veins $(71 \%)$ were detected by Doppler angiography, but there were no false-positive results in these patients.

Closer correlation was found between the two methods when thrombi completely occluded the popliteal and femoral veins; five out of six popliteal vein thrombi $(83 \%)$ and all six femoral vein thrombi were detected by Doppler angiography.

\section{Discussion}

Venous thromboembolic disease is among the most serious and frequent complications observed in hospital patients. Clinical diagnosis is highly unreliable, and during the past few years several techniques have been developed for confirming the presence or absence of deep vein thrombosis. They include the radioactive fibrinogen uptake test, electrical impedance plethysmography, and the ultrasonic method.

Although the ultrasonic technique is the simplest of all available methods, it has many limitations, owing mainly to the inability of the conventional ultrasonic flow detector to distinguish between normal venous flow signals and signals produced by blood passing by a non-occluding thrombus in a major vein or large dilated collateral vessel. Our results indicate that ultrasonic angiography overcomes the disadvantages of the continuous-wave Doppler flowmeter while retaining its advantages of simplicity and noninvasion. It was successful in 30 $(94 \%)$ but of 32 limbs in detecting thrombi shown by venography. In 12 limbs venography detected thrombi completely occluding the popliteal and femoral veins; $11(92 \%)$ of these were detected by ultrasonic angiography. The results were less satisfactory for thrombi partially occluding the popliteal and femoral veins, only $9(69 \%)$ out of 13 such thrombi being detected. This was also the case for thrombi confined to the calf veins; only $18(64 \%)$ out of 28 such thrombi were detected. Though less encouraging, these findings are much more accurate than those of our previous study, ${ }^{13}$ in which only $13(28 \%)$ out of 46 such thrombi were detected by the Doppler flowmeter. Similar findings have been reported by others. ${ }^{14} 15$

It may be argued that the failure of the Doppler flowmeter to detect calf-vein thrombi is not a serious disadvantage, since such thrombi rarely produce major pulmonary embolism. ${ }^{3}$ Though a surprisingly high proportion of calf-vein thrombi undergo spontaneous lysis, some $20 \%$ of them extend more proximally from the calf into the popliteal, femoral, and iliac veins. ${ }^{16}$ Pulmonary embolism occurs in almost half of such cases, but only a few prove fatal. ${ }^{16}$ Furthermore, minor calfvein thrombi may cause longlasting symptoms. ${ }^{17}$ If the Doppler flowmeter were used to confirm the diagnosis partially occluding thrombi, which may propagate in the major veins, or minor thrombi in the calf veins would be easily missed. This has been confirmed by a survey in which routine screening with the Doppler flowmeter was carried out for one year in two surgical wards $; 4137$ patients over the age of 35 undergoing major abdominal surgery were studied. Apart from calf-vein thrombi, non-occlusive iliofemoral thrombi were also missed and two patients died from pulmonary embolism. The true value of Doppler angiography will be established only by further studies designed on these lines.

The disadvantages of ultrasonic angiography are that the instrument is cumbersome and a trained technician needs about 20 minutes to examine both limbs. Further work is in progress to simplify and increase the accuracy of the instrument and the procedure so that the method may eventually be suitable for routine screening of "at-risk" patientş.

We thank the Department of Health and Social Security for a grant to carry out this work, and the Medical Research Council (programme grant G973/756) for providing a fellowship for TKD.

Requests for reprints should be addressed to Mr P J Fish, Department of Medical Physics, King's College Hospital Medical School, Denmark Hill, London SE5 8RX.

\section{References}

1 Strandness, D E, et al, American fournal of Surgery, 1967, 113, 311.

2 Sigel, B, et al, Surgery, Gynecology and Obstetrics, 1968, 127, 339.

${ }^{3}$ Evans, D S, and Cockett, F G, British Medical fournal, 1969, 2, 802.

${ }^{4}$ Negus, D, and Rickford, C R K, Proceedings of the Royal Society of Medicine, 1974, 67, 703.

${ }^{5}$ Browse, N, British Medical fournal, 1969, 4, 676.

6 Fish, P J, in Blood Flow Measurement, ed V C Roberts, p 29. London, Sector Publishing, 1972.

${ }^{7}$ Hokanson, D E, et al, Radiology, 1972, 102, 435.

8 Mozersky, D J, et al, Surgery, 1972, 72, 253.

${ }^{9}$ Fish, P J, et al, Lancet, 1972, 1, 1269.

10 Fish, P J, in Proceedings of 2nd European Congress on Ultrasonics in Medicine (Munich), 1975. In press.

${ }^{11}$ Nicolaides, A N, et al, in Thromboembolism: Diagnosis and Treatment, ed V V Kakkar and A J Jouhar, p 69. London, Churchill Livingstone, 1972

12 Kakkar, V V, Milbank Memorial Fund Quarterly, 1972, 1, 206.

${ }^{13}$ Kakkar, V V, in Proceedings of 2 nd Congress of International Society of Thrombosis and Haemostasis, p 233. Stuttgart, Schattauer, 1971.

14 Strandness, D E, and Sumner, D S, Archives of Surgery, 1972, 104, 180.

15 Milne, R M, et al, Lancet, 1971, 2, 445.

16 Kakkar, V V, et al, Lancet, 1969, 2, 230.

17 Browse, N L, and Clemenson, G, British Medical fournal, 1974, 2, 468. 